\title{
On The Relation Between Regulation And Economic Growth
}

Atul A. Dar, Saint Mary's University, Canada

Sal AmirKhalkhali, Saint Mary's University, Canada

\begin{abstract}
This paper examines the relation between regulation and economic performance in the context of 23 developed economies. We apply a generalisation of the growth accounting model popularized by Solow to data over the 2002-2008 period. In the model, we assume that regulatory quality impacts on growth via its impact on total factor productivity growth. We look at three measures of regulatory quality, all of which are based on the set of governance indicators developed by the World Bank. The model is estimated using a fixed effects as well as a random effects estimation strategy. Our findings do lend support for the view that the better the quality of regulation, the higher rate of economic growth, but find no support for the view that the strength of the positive growth impact is stronger for countries that rank relatively lower on the regulatory quality scale.
\end{abstract}

Keywords: Regulation; Total Factor Productivity; Economic Growth

\section{INTRODUCTION}

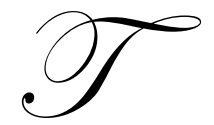

he link between institutional factors and economic performance has been studied from many angles. One that has been explored at length is the role that freedom (economic and political) plays in promoting economic performance - see, for instance, Doucouliagos and Ulubasoglu (2006), Breggon (2003), Klein and Luu (2003), Scully (2002), de Haan and Sturm (2000), Nelson and Singh (1998). Attention has also been given to the relationship between governance and economic performance (Kauffman and Kraay, 2002), Hall and Jones (1999), Olson, Sarna and Swamy (1998), and Barro (1997). In this study, we narrow the focus by looking at the effect of the quality of regulation on economic growth in OECD countries. Of course, the institutional set-up is a key determinant of the type and quality of the regulatory framework, and of economic growth. Although the question of the impact of regulation on economic growth appears to be most relevant in a context where there is considerable weakness in the institutional set-up (i.e. developing economies), our focus on OECD countries is predicated on the grounds that there can also be perceptibly large differences in the quality of regulation among developed countries as well.

The empirics of growth has long relied on some variant of the basic aggregate growth-accounting model developed by Solow (1956), with more generalized approaches incorporating theoretical insights offered by endogenous growth theory - see, for instance, Barro (1991, 2000), Barro and Salai-i-Martin (1992), Jones (1995), and Mankiw, Romer and Weil (1992), AmirKhalkhali and Dar (2003)]. An important element of studies such as these is that economic growth is seen as depending not just on traditional variables like factor accumulation, but also upon various institutional factors. Typically, in such models, various variables reflecting institutional characteristics are included as affecting growth via their impact on total factor productivity - the "Solow" residual. In reality, there is no unique variable that can capture the multi-dimensional aspects of a country's institutional structure; as a result, there are potentially many ways of studying the impact of institutions. Our study modifies the growth-accounting model used by Dar and AmirKhalkhali (2003) to examine whether the quality of regulatory framework plays a prominent role in explaining differences in growth rates in these countries. We use measures of the quality of regulation that are drawn from the governance indicators developed by the World Bank. Our analysis covers the 2002-2008 interval for 23 OECD countries for which continuous annual data on these indicators are available, and we estimate our model using fixed and random effects methodology. 
The rest of the paper is organized as follows. In Section II, we discuss the model, the data and the estimation techniques. Section III contains a discussion of our empirical findings, while Section IV concludes with a summary of the findings.

\section{THE EMPIRICAL MODEL, DATA \& ESTIMATION}

It is well known from the theory of second-best that the impact of regulation in offsetting welfare reductions because of distortions resulting from imperfect markets and externalities is not certain. This is the case even when regulators have full information and are guided by public interest. Further, despite significant theoretical advances in the literature on regulation, not much is known about the macroeconomic implications. This paper seeks to address this gap empirically. The real issue is not so much whether regulation has positive or negative effects on macroeconomic outcomes; rather, given that regulation is a fact of life in all economies, the relevant question is whether the quality of regulation matters. Are countries in which the institutional framework is more conducive to the formulation and implementation of effective regulatory policies also more likely to have better macroeconomic outcomes? This is the question posed in this study.

The difficulty in measuring the quality of regulation has meant that not many studies have been able to empirically look at this question, and those that have, have looked at more general governance indicators, and estimated their impact of various macroeconomic variables, as noted above. The greater availability of panel data for a large number of countries in recent years has given added impetus to the study of this question, especially since the data more directly attempt to measure regulatory quality. It is, of course, expected that the study of the potential impact of the quality of regulations would be most relevant in poor countries, where the supporting institutional structure is likely to be weak. A panel study of developing countries by Jalilian, Kirkpatrick and Parker (2006), for instance, found that growth in poor countries is positively related to regulatory quality. That notwithstanding, even among developed countries, regulatory quality can vary quite significantly, and thus can lead to variations in economic growth. Hence, in this paper, we confine our analysis to twenty three OECD countries. Our aim is to use World Bank regulatory quality indicators to assess whether variations in regulatory quality across nations is relevant for explaining differences in their growth rates over the 2002-2008 interval.

The World Bank publishes data on six governance indicators, of which two are more clearly measures of regulatory quality. These are the government effectiveness index (GE) and the regulatory quality index (RQ). The raw information that are inputs in measuring these indicators are drawn from a variety of sources (national and international) - see Kauffman, Kraay and Mastruzzi (2009) for details. As noted by Jalilian et al. (2006, p. 91), RQ and GE can be taken as indicators that best reflect the two main dimensions of regulation - the quality of outcomes and the process through which regulation comes about. Thus, RQ tries to measure the economic burden on business through quantitative regulations, price controls and other interventions, which can be taken as indicators of the quality of outcomes; GE, on the other hand, attempts to measure the quality of the public sector bureaucracy, including the credibility of government decisions, and thus indicates the quality of the process of regulatory governance. Both indices are constructed such that higher scores (in the -2.5 to +2.5 range), indicate a better quality of regulation. In this paper, we use three measures of regulatory quality: GE, RQ, and an aggregate measure, which is a simple arithmetic average of GE and RQ, henceforth referred to as GERQ. Ideally, we would like RQ and GE to be independent of each other - that way, each would contain different sets of information. This condition is not met in the sample since the correlation coefficient between the two is 0.69 , which is not trivial. Nonetheless, there are sufficient differences between the two for them to be used separately for assessing the question posed above.

As noted earlier, the model we adopt is a generalized version of the growth accounting, production function model of Solow in which the rate of economic growth is a function of capital and labour accumulation and total factor productivity. The standard growth accounting model can be written as:

$\mathrm{GY}_{\mathrm{it}}=\mathrm{A}_{\mathrm{it}}+\alpha_{1} \mathrm{GK}_{\mathrm{it}}+\alpha_{2} \mathrm{GL}_{\mathrm{it}}$

where GY is the rate of growth of real GDP, GK is the rate of real capital accumulation, GL is the rate of growth of the labour force, and $\mathrm{A}_{\mathrm{it}}$ measures the rate of total factor productivity growth, or more accurately, the Solow residual. The subscripts $\mathrm{i}(\mathrm{i}=1,2, \ldots, \mathrm{n})$ and $\mathrm{t}(\mathrm{t}=1,2, \ldots, \mathrm{T})$ index the countries and time periods in the sample, 
respectively. Generalizations of the model are usually generated by identifying measurable variables that capture the economic and/or political structure of a country, and which affect growth via total factor productivity. For instance, two common variables included are those that measure the size of government in the economy and its openness to trade, or export expansion - see, for instance, Amirkhalkhali and Dar (2003). Our generalization models total factor productivity as depending upon export growth and regulatory quality, as well as upon other unmeasured differences across countries. As a result, we can write:

$\mathrm{A}_{\mathrm{it}}=\alpha_{\mathrm{i} 0}+\alpha_{3} \mathrm{GX}_{\mathrm{it}}+\alpha_{4} \mathrm{R}_{\mathrm{it}}+\mathrm{u}_{\mathrm{it}}$

where GX is the rate of export growth, $\mathrm{R}$ is a regulatory quality index, $\mathrm{u}$ is the time and country specific random disturbance and $\alpha_{i 0}$ measures unmeasured cross-country but time-invariant differences. Substituting (2) in (1) yields

$\mathrm{GY}_{\mathrm{it}}=\alpha_{\mathrm{i} 0}+\alpha_{1} \mathrm{GK}_{\mathrm{it}}+\alpha_{2} \mathrm{GL}_{\mathrm{it}}+\alpha_{3} \mathrm{GX}_{\mathrm{it}}+\alpha_{4} \mathrm{R}_{\mathrm{it}}+\mathrm{u}_{\mathrm{it}}$

In (3), in the absence of capital stock data, it is not possible to measure the rate of capital formation (GK). A common approach is to use other candidates, such as the investment rate (IY); we follow this procedure. We also use the growth rate of employment rather than total labour force growth for GL because, given the existence of persistent episodes of unemployment in these countries over the sample period, employment more accurately captures the extent of labour utilization. Our prior expectations are that all slope coefficients are positive (or, at least, non-negative). We estimate (3) using each of the three measures of regulatory quality $\mathrm{R}: \mathrm{GERQ}=(\mathrm{GE}+\mathrm{RQ}) / 2$, GE and RQ. An interesting question is the strength of the impact of regulatory quality on growth, and how this impact varies across countries. To examine this, we construct the elasticity of growth with respect to regulatory quality. One might expect that the greatest beneficial growth impact from regulatory improvements occur in a situation where the quality of regulation is low to begin with. This would imply that the growth elasticity is inversely related to regulatory quality.

Table 1: Averages of Variables (2002-2006): OECD Countries

\begin{tabular}{|l|c|c|c|c|c|c|c|}
\hline \multicolumn{1}{|c|}{ Country } & GY & IY & GL & GERQ & GE & RQ & GX \\
\hline Australia & 3.26 & 27.53 & 1.07 & 1.71 & 1.81 & 1.61 & -5.49 \\
\hline Austria & 2.37 & 22.70 & 2.45 & 1.67 & 1.77 & 1.57 & -0.9 \\
\hline Belgium & 1.96 & 21.42 & 1.28 & 1.48 & 1.67 & 1.30 & -1.90 \\
\hline Canada & 2.38 & 21.64 & 1.96 & 1.71 & 1.85 & 1.55 & -4.20 \\
\hline Denmark & 1.33 & 21.31 & 0.53 & 1.95 & 2.14 & 1.75 & -1.91 \\
\hline Finland & 2.86 & 21.01 & 0.96 & 1.88 & 2.08 & 1.69 & -1.69 \\
\hline France & 1.62 & 20.44 & 0.67 & 1.41 & 1.61 & 1.20 & -1.69 \\
\hline Germany & 1.20 & 17.59 & 0.79 & 1.52 & 1.55 & 1.50 & 0.39 \\
\hline Greece & 3.87 & 21.68 & 1.59 & 0.84 & 0.81 & 0.89 & -3.14 \\
\hline Iceland & 4.12 & 25.52 & 2.99 & 1.70 & 1.91 & 1.49 & 0.54 \\
\hline Ireland & 4.30 & 24.98 & 1.13 & 1.65 & 1.61 & 1.69 & -0.57 \\
\hline Italy & 0.77 & 21.14 & 1.69 & 0.80 & 0.66 & 0.95 & -5.41 \\
\hline Japan & 1.41 & 23.36 & -0.05 & 1.18 & 1.30 & 1.05 & -0.09 \\
\hline Luxembourg & 3.92 & 21.43 & 3.29 & 1.76 & 1.78 & 1.74 & 1.86 \\
\hline Netherlands & 1.94 & 19.76 & 0.91 & 1.78 & 1.85 & 1.72 & -0.99 \\
\hline New Zealand & 2.95 & 23.51 & 2.25 & 1.72 & 1.76 & 1.68 & -0.99 \\
\hline Norway & 2.37 & 20.84 & 1.48 & 1.63 & 1.92 & 1.34 & -4.21 \\
\hline Portugal & 0.81 & 23.73 & 0.24 & 1.12 & 1.07 & 1.17 & -1.67 \\
\hline Spain & 3.02 & 28.97 & 3.27 & 1.29 & 1.34 & 1.25 & -1.74 \\
\hline Sweden & 2.57 & 18.36 & 1.161 & 1.76 & 1.94 & 1.57 & -0.81 \\
\hline Switzerland & 2.04 & 21.40 & 1.16 & 1.77 & 1.95 & 1.59 & -0.77 \\
\hline UK & 2.31 & 17.18 & 1.04 & 1.72 & 1.73 & 1.70 & -2.43 \\
\hline US & 2.31 & 19.37 & 0.92 & 1.57 & 1.60 & 1.54 & -1.17 \\
\hline
\end{tabular}

Notes: GY = annual real GDP growth (\%); IY = investment to GDP ratio; GL is labour force growth (\%); GERQ= (GE+RQ)/2, where GE is the government effectiveness index and RQ is the regulatory quality index; GX= export growth rate.

In estimating (3), it can be noted that, since the intercept $\alpha_{i 0}$ is country-specific, the use of least squares by pooling the data would be inappropriate. In light of this, the two options that suggest themselves are fixed effects and 
random effects estimation. If we treat the $\alpha_{\mathrm{i} 0}$ as random variables, which are independent of the regressors, then random effects estimation is efficient. If, on the other hand, we treat them as fixed parameters, then fixed effects estimation is consistent regardless of whether the fixed effects are correlated with the regressors or not. However, fixed effects estimation is not efficient. In this scenario, one would opt for random effects estimation. However, if the $\alpha_{\mathrm{i} 0}$.are correlated with the regressors, which is often quite likely, then random effects estimation is inconsistent, and there is case for using the fixed effects estimator. Our approach involves estimating the model (3) using both fixed and random effects estimation, and then using them to test for the appropriate estimation technique. Specifically, we can apply the standard F statistic to test the fixed effects assumption, and the Hausman Chi-square statistic to then test whether the null hypothesis that the random effects approach is supported by the evidence.

As noted before, the sample used in this study consists of data for twenty three industrialized countries which are members of OECD: Australia, Austria, Belgium, Canada, Denmark, Finland, France, Germany, Greece, Iceland, Ireland, Italy, Japan, Luxembourg, Netherlands, New Zealand, Norway, Portugal, Spain, Sweden, Switzerland, the United Kingdom, and the United States. The data span the 2002-2008 interval and were obtained from various issues of Economic Outlook published by OECD and International Financial Statistics published by International Monetary Fund (IMF). Table 1 above presents averages of the variables used in this study. It is quite evident that even among this group of industrial countries, there are fairly large differences in the quality of regulation, as can be seen by examining the three indicators, GE, RG and GERQ. Both the GE and RQ index suggest that countries such as Greece and Italy have the poorest regulatory quality, while countries like Finland, Denmark and Luxembourg score the highest in this regard. Annual rates of economic growth also shows much variability across the panel, ranging from a low average of only 0.85 percent in Italy to a high of 3.9 percent in Luxembourg. It does appear to be the case from casual examination of the data in Table 1 that economic growth is positively associated with regulatory quality. We explore this in greater detail in the next section.

\section{EMPIRICAL FINDINGS}

The estimates of equation (3) are reported in Table 2 below. Regardless of the regulatory measure used, the random effects estimates indicate that a higher quality of regulation leads to stronger economic growth, and the relevant coefficients are significant at the 5 percent with the GERQ and GE measures. With fixed effects, the same is true of the coefficients of GERQ and GE measures, but the coefficient of RQ is negative, but highly insignificant. As well, capital accumulation and labour force growth impact positively on growth in all regressions, and the coefficients significant at 1 percent or less. The coefficient of export growth has the expected positive sign, but is not significant at the 10 percent level except in the case of using fixed effects with GE measure.

Table 2: Fixed Effects \& Random Effects Estimates (N=23, $\mathrm{T}=7$ )

\begin{tabular}{|c|c|c|c|c|c|c|}
\hline & Fixed Effects & Random Effects & Fixed Effects & Random Effects & Fixed Effects & Random Effects \\
\hline Constant & $*$ & $\begin{array}{c}-2.602 \\
(-1.945)\end{array}$ & $*$ & $\begin{array}{c}-2.683 \\
(-2.067)\end{array}$ & $*$ & $\begin{array}{c}-1.961 \\
(-1.461)\end{array}$ \\
\hline GERQ & $\begin{array}{c}2.034 \\
(1.954)\end{array}$ & $\begin{array}{c}1.072 \\
(2.246)\end{array}$ & $*$ & $*$ & $*$ & $*$ \\
\hline GE & $*$ & $*$ & $\begin{array}{c}2.112 \\
(2.285) \\
\end{array}$ & $\begin{array}{c}0.974 \\
(2.530) \\
\end{array}$ & $*$ & $*$ \\
\hline RQ & $*$ & $*$ & $*$ & $*$ & $\begin{array}{c}-0.165 \\
(-0.096) \\
\end{array}$ & $\begin{array}{c}0.840 \\
(1.530) \\
\end{array}$ \\
\hline IRATE & $\begin{array}{l}0.1750 \\
(2.553) \\
\end{array}$ & $\begin{array}{c}0.130 \\
(2.740) \\
\end{array}$ & $\begin{array}{c}0.205 \\
(2.941) \\
\end{array}$ & $\begin{array}{c}0.137 \\
(2.821) \\
\end{array}$ & $\begin{array}{c}0.157 \\
(2.287) \\
\end{array}$ & $\begin{array}{c}0.121 \\
(2.569) \\
\end{array}$ \\
\hline GL & $\begin{array}{l}0.3766 \\
(4.272) \\
\end{array}$ & $\begin{array}{c}0.406 \\
(4.324) \\
\end{array}$ & $\begin{array}{c}0.384 \\
(4.385) \\
\end{array}$ & $\begin{array}{c}0.410 \\
(4.385) \\
\end{array}$ & $\begin{array}{c}0.362 \\
(3.568) \\
\end{array}$ & $\begin{array}{c}0.403 \\
(4.256) \\
\end{array}$ \\
\hline GX & $\begin{array}{l}0.0546 \\
(1.597)\end{array}$ & $\begin{array}{c}0.047 \\
(1.222)\end{array}$ & $\begin{array}{c}0.058 \\
(1.670)\end{array}$ & $\begin{array}{c}0.047 \\
(1.244)\end{array}$ & $\begin{array}{c}0.040 \\
(1.235)\end{array}$ & $\begin{array}{c}0.047 \\
(1.225)\end{array}$ \\
\hline R-squared & 0.45 & 0.26 & 0.47 & 0.27 & 0.44 & 0.26 \\
\hline F $(22,134)$ & 2.04 & $*$ & 2.27 & $*$ & 1.94 & $*$ \\
\hline Chi-square & $*$ & 1.24 & $*$ & 2.24 & $*$ & 0.64 \\
\hline
\end{tabular}

Notes: Numbers in parentheses are t ratios; the F statistic tests for the fixed effects model vs. the OLS model (null hypothesis); while the Chi-square statistic tests for random effects (null hypothesis) vs. fixed effects; for variable definitions, see notes to Table 1; the dependent variable in all equations is GY, the annual growth rate of real GDP. 
It is interesting to note that the estimated coefficients of all the regulation variables (as well as the investment rate variable) are all smaller in magnitude under the random effects specification. This raises the question as to which of the two models gives better estimates. First, note that the F statistic in all fixed effects equations is statistically significant at the 1 percent level. This would imply that the data strongly support the fixed effects specification vis-a-vis the pooled OLS model. This means that unobserved heterogeneity is present and least squares estimation is biased and inconsistent. On the other hand, the Hausman Chi-square test statistic is not statistically significant at even the 10 percent level of significance in all cases. This finding thus supports the validity of the random effects model.

Returning to the estimated effects of regulation, we can give a more precise interpretation to their magnitude. Specifically, we can calculate the growth elasticities with respect to regulation. These estimates are provided in Table 3 below. Note first that the estimated growth elasticities average in the 0.6-0.8 range, depending upon the regulation measure used. Thus, on average, improved regulation does not have a very strong impact on growth, although that impact is not trivial because the elasticities vary quite significantly, suggesting that countryspecific estimates could paint a different picture. Thus, the elasticities range from lows in the 0.19-0.23 range to highs in the 1.2-1.6 range. The countries at the high end are: Denmark, Italy, Portugal and Germany while the country at the bottom of the spectrum is Greece, regardless of the regulatory measure used. In any case, only the four countries listed above (out of a total of 23) have elasticities in excess of unity. So the impact of regulation is generally not strong for most countries the OECD group. As well, note that Greece is the country which ranks the lowest in terms of regulatory quality, regardless of the measure used, while Denmark is among the countries with the highest regulatory quality. It would, therefore, appear that countries with the poorest regulatory quality do not appear to benefit most in terms of growth from an improvement in regulatory quality. To assess this more rigorously, we computed the correlations between the growth elasticities and each of our regulation measures. Our results found that these correlations are every weak and highly insignificant statistically, implying that the impact of regulation on growth is independent of regulation itself. Overall, thus, our findings suggest that improved regulatory quality does appear to benefit growth in developed countries, but the impact is not very strong, except for a handful of countries, and the strongest impact does not appear to be in those countries which are at the lower end of the regulatory quality spectrum.

Table 3: Growth Elasticities: 2002-2008

\begin{tabular}{|l|c|c|c|c|}
\hline Regulation measure & Mean Elasticity & Standard Deviation & Maximum & Minimum \\
\hline GERQ & 0.81 & 0.34 & 1.57 & 0.23 \\
\hline GE & 0.77 & 0.32 & 1.57 & 0.20 \\
\hline RQ & 0.60 & 0.27 & 1.21 & 0.19 \\
\hline
\end{tabular}

\section{CONCLUSION}

This paper empirically examined the impact of the quality of regulation on economic growth on OECD countries over the 2002-2008 interval, using indicators of regulatory quality developed by the World Bank. Our estimates provide support forlthe view that the quality of regulation has a positive impact on growth, although the strength of that evidence varied across indicators. However, the prior expectation that the strength of the favourable impact of improved regulatory quality, as measured by the elasticity of growth with respect to regulation, would likely be greater for countries with a relatively poorer quality was not supported by the evidence. How robust these findings are, is a matter for further investigation. One area for further analysis is the estimation methodology. We have used fixed and random effects estimation since they take into account unobserved cross-country heterogeneity. In that regard, a random coefficients approach would likely be a better estimation strategy since such an approach can be shown to be a more appropriate statement of the law relating growth to its determinants. With random coefficients, all coefficients vary across countries, and this would mean that regulation impacts growth not just through its impact on total factor productivity, but through individual factor productivity as well. Additionally, applying such an approach by grouping countries according to the level of regulatory quality would also provide more insight on how regulation impacts on growth. 


\section{AUTHOR INFORMATION}

Dr. Atul Dar is full professor of Economics at Saint Mary's University, Halifax, Canada. He joined the university in 1981. He also worked as an economist in a research capacity at the Royal Bank of Canada while on a leave of absence during 1985-86. Since joining the Economic Department, he has taught a wide variety of courses, and his research appears in a number of refereed academic journals, including the Journal of Policy Modeling, Journal of Risk and Insurance, Applied Economics, Economic Modelling, Empirical Economics, Canadian Journal of Economics, Journal of Development Studies, Southern Economic Journal, and IMF Staff Papers. E-mail: atul.dar@smu.ca. Corresponding author.

Dr. Sal AmirKhalkhali is full professor of Economics at Saint Mary's University. He has published papers on the theory of econometrics, and empirical articles dealing with fiscal policy, capital mobility, and economic growth. His publications include book chapters and articles in refereed journals such as Canadian Journal of Economics, Canadian Public Administration, Canadian Public Policy, Canadian Tax Journal, Applied Economics, Development Policy Review, Eastern Economic Journal, Economic Modeling, Economic Notes, Empirical Economics, IMF Staff Papers, Journal of Policy Modeling, Southern Economic Journal, Communications in Statistics, Sankhya (published by Indian Statistical Society), Journal of Statistical Computation and Simulation, and The Statistician.

\section{REFERENCES}

1. AmirKhalkhali, S. and A. Dar (2003), On Explaining the Differences in Economic Growth Rates in OECD Countries, Ekonomia, 2003, 6 (2): 147-59.

2. Barro, R. J. (1991), Economic Growth in a Cross Section of Countries, Quarterly Journal of Economics, 106: 407-33.

3. Barro, R. J. (1997), Determinants of Economic Growth: A Cross-Country Empirical Study, Development Discussion Paper No. 579, Harvard Institute for International Development.

4. Barro, R and X. Sala-i-Martin (1992), Convergence, Journal of Political Economy, 100: 223-51.

5. Berggren, N. (2003), The Benefits of Economic Freedom: A Survey, The Independent Review, 8: 193-211.

6. Dar, A. and S. AmirKhalkhali (2003), On the Impact of Trade Openness on Growth: Further Evidence from OECD Countries, Applied Economics, 2003, 35: 1761-66.

7. de Haan, J. and J.E. Sturm (2000), On the Relationship Between Economic Freedom and Economic Growth, European Journal of Political Economy, 16(2): 215-41.

8. Doucouliagos, H. and M. Ulubasoglu (2006), Democracy and Economic Growth: A Meta-Analysis, Working paper, School of Accounting, Economics and Finance, Deakin University, Australia.

9. Hall, R.E. and C. Jones (1999), Why Do Some Countries Produce So Much More Output per Worker than Others? Quarterly Journal of Economics, 114(1): 83-116.

10. Jalilian, H., C. Fitzpatrick, and D. Parker (2006), The Impact of Regulation on Economic Growth: A CrossCountry Analysis, World Development, 35(1): 87-103.

11. Jones, C.I. (1995), Time Series Tests of Endogenous Growth Models, Quarterly Journal of Economics, 110: 495-525.

12. Kaufmann, D., A. Kraay, and M. Mastruzzi (2009), Governance Matters VIII: Aggregate and Individual Governance Indicators, 1996-2008, World Bank Policy Research Working Paper 4978.

13. Kauffman, D. and A. Kraay (2002), Growth Without Governance, mimeo, Washington DC: World Bank.

14. Klein, P.G. and H. Luu (2003), Politics and Productivity, Economic Inquiry, 41(3): 433-47.

15. Mankiw, N.D., P. Romer, and D. Weil (1992), A Contribution to the Empirics of Economic Growth, Quarterly Journal of Economics, 107: 407-37.

16. Nelson, M.A. and R. D. Singh (1998), Democracy, Economic Freedom, Fiscal Policy, and Growth in LDCs: A Fresh Look, Economic Development and Cultural Change, 46(4): 677-96.

17. Olson, M., N. Sarna and A.V. Swamy (1998), Governance and Growth: A Simple Hypothesis Explaining Cross-Country Differences in Productivity, mimeo, Centre for Institutional Reform and the Informal Sector, University of Maryland, USA.

18. Scully, G.W. (2002), Economic Freedom, Government Policy and the Trade-Off between Equity and Economic Growth, Public Choice, 113(1-2): 77-96.

19. Solow, R.M. (1956), A Contribution to the Theory of Economic Growth, Quarterly Journal of Economics, 70: 65-94. 